\title{
Formation Mechanism for Hexagonal-Structured Self-Assemblies of Nanocrystalline Titania Tem- plated by Cetyltrimethylammonium Bromide
}

\author{
Toshio Sakai ${ }^{\text {* }}$, Hanae Yano ${ }^{2}$, Mitsuru Ohno ${ }^{2}$, Hirobumi Shibata ${ }^{3}$, Kanjiro Torigoe ${ }^{4}$, \\ Shigenori Utsumi ${ }^{2}$, Kazutami Sakamoto ${ }^{2}$, Naokiyo Koshikawa ${ }^{5}$, Satoshi Adachi ${ }^{5}$, \\ Hideki Sakai ${ }^{2,4}$ and Masahiko Abe ${ }^{2,4}$ \\ ${ }_{1}^{1}$ International Young Researchers Empowerment Center, Shinshu University (Wakasato, Nagano 380-8553, JAPAN) \\ ${ }^{2}$ Faculty of Science and Technology, Tokyo University of Science (Noda, Chiba 278-8510, JAPAN) \\ ${ }^{3}$ Faculty of Industrial Science and Technology, Tokyo University of Science (Noda, Chiba 278-8510, JAPAN) \\ ${ }^{4}$ Research Institute for Science and Technology, Tokyo University of Science (Noda, Chiba 278-8510, JAPAN) \\ ${ }^{5}$ Japan Aerospace Exploration Agency (Tsukuba, Ibaraki, 305-8505, JAPAN)
}

\begin{abstract}
Hexagonal-structured self-assemblies of nanocrystalline (anatase) titania templated by cetyltrimethylammonium bromide $\left(\mathrm{C}_{16} \mathrm{H}_{33} \mathrm{~N}\left(\mathrm{CH}_{3}\right)_{3} \mathrm{Br}\right.$; CTAB) (Hex-ncTiO ${ }_{2} / \mathrm{CTAB}$ Nanoskeleton) were formed after mixing of aqueous solutions containing $\mathrm{CTAB}$ spherical micelles and titanium oxysulfate acid hydrate $\left(\mathrm{TiOSO}_{4} \cdot \mathrm{xH}_{2} \mathrm{SO}_{4} \cdot \mathrm{xH}_{2} \mathrm{O}\right)$ as a titania precursor in the absence of any other additives. Formation

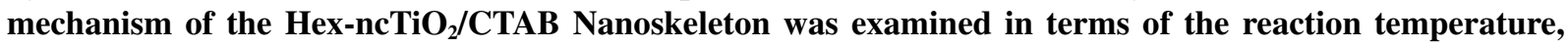
titania precursor/CTAB mixing ratio, surfactant type, electrostatic interaction, micelle formation and molecular component. We found that crystal growth of crystalline (anatase) titania (polymorphic crystallization) was promoted with higher temperature and lower titania precursor content in aqueous solutions. In addition, we revealed that the crystalline (anatase) titania was formed in polycation, poly(allylamine hydrochloride $\left(\left[\mathrm{CH}_{2} \mathrm{CH}\left(\mathrm{CH}_{2} \mathrm{NH}_{2}\right) \mathrm{HCl}\right]_{n} ; \mathrm{PAH}\right)$, and formamide $\left(\mathrm{HCONH}_{2}\right)$ solutions. On the other hand, no titania formation was observed in anionic systems such as sodium dodecyl sulfate $\left(\mathrm{CH}_{3}\left(\mathrm{CH}_{2}\right)_{11} \mathrm{OSO}_{3} \mathrm{Na}\right.$; SDS) and poly(sodium 4-styrenesulfonate $\left(\left[\mathrm{C}_{8} \mathrm{H}_{7} \mathrm{SO}_{3} \mathrm{Na}\right]_{n}\right.$; PSSS). This indicates that hydrolysis reaction of the titania precursor is initiated by not only cations but also nitrogen atoms in molecules and polymers. Hexagonally structure was formed in only cationic surfactant micellar solutions but not in polycation solutions and formamide.
\end{abstract}

Key words: hexagonal-structured self-assemblies, nanocrystalline titania, Nanoskeleton, cetyltrimethylammonium bromide, titanium oxysulfate acid hydrate

\section{INTRODUCTION}

Amphiphilic molecules and polymers are widely used as dispersion stabilizers ${ }^{1-3)}$, pharmaceutical ingredients ${ }^{4,5)}$ or biomedical materials ${ }^{6,7)}$. In addition to the such advantages of amphiphilic molecules and polymers, self-assemblies of the amphiphilic molecules and polymers are very useful for mesoporous material synthesis as structure-directing agents and/or templates ${ }^{8-11)}$. For example, well-ordered hexagonal mesoporous silica structures (e.g., MCM-41, SBA-15) can be synthesized through hydrolysis of tetraethoxysilane (TEOS) in cetyltrimethylammonium chloride (CTACl) solutions ${ }^{12,13)}$ or hexagonal lyotropic liquid crystals afforded by poly(ethylene oxide)-poly(propylene oxide) block copolymers ${ }^{14-19)}$. Namely, combination of selfassembly with sol-gel chemistry is a promising route for the ordered mesoporous material synthesis. Therefore, the judicious selection of inorganic precursors, amphiphilic molecules and polymers is an important task for designing of mesoporous materials ${ }^{8-19)}$.

We have recently found a unique combination;

${ }^{*}$ Correspondence to: Toshio Sakai, International Young Researchers Empowerment Center, Shinshu University, Wakasato, Nagano 3808553, JAPAN

E-mail: tsakai@shinshu-u.ac.jp

Accepted June 27, 2008 (received for review May 28, 2008)

Journal of Oleo Science ISSN 1345-8957 print / ISSN 1347-3352 online

http://www.jstage.jst.go.jp/browse/jos/ 
cetyltrimethylammonium bromide $(\mathrm{CTAB})$ and titanium oxysulfate acid hydrate $\left(\mathrm{TiOSO}_{4} \cdot \mathrm{xH}_{2} \mathrm{SO}_{4} \cdot \mathrm{xH}_{2} \mathrm{O}\right)$ as a titania precursor, to form hexagonal-structured self-assemblies of nanocrystalline anatase titania $\left(\mathrm{Hex}-\mathrm{nc} \mathrm{TiO}_{2} / \mathrm{CTAB}\right.$ Nanoskeleton $)^{20,21}$. The Hex-ncTiO ${ }_{2} / \mathrm{CTAB}$ Nanoskeleton was prepared through a hydrolysis reaction of the titania precursor promoted by CTAB spherical micelles in aqueous solutions at $60^{\circ} \mathrm{C}$ for $24 \mathrm{~h}^{20,211}$. Compared to the reported methods for mesoporous titania synthesis ${ }^{22-27)}$, our system involves unique features and advantages, for example, a facile preparation, utilization of water as a solvent, hexagonal-structure autoformation in solutions (without solvent evaluation), crystallization of titania in aqueous solutions in mild conditions (e.g., at $60^{\circ} \mathrm{C}$ for $\left.24 \mathrm{~h}\right)^{20,21)}$ while crystallization of mesoporous titania normally requires calcinations at high temperature ${ }^{22-27)}$. To realize the full potential of our approach (and to be able to generalize to other systems) we need better insight on the HexncTiO ${ }_{2} / \mathrm{CTAB}$ Nanoskeleton formation.

In this work, we examined the effects of temperature, titania precursor/CTAB mixing ratio, surfactant type, electrostatic interaction, micelle formation and molecular component on the crystal growth, hydrolysis reaction initiation and hexagonally structure formation. We found that temperature and titania precursor/CTAB mixing ratio can control the crystal growth. The hydrolysis reaction of the titania precursor was initiated in cationic surfactant (CTAB), polycation (poly(allylamine hydrochloride); $\mathrm{PAH}$ ) and formamide solutions but not in anionic surfactant (sodium dodecyl sulfate; SDS) and polyanion (poly(sodium 4-styrenesulfonate); PSSS) solutions. This indicates that interactions between cations (and/or nitrogen atoms) and the titania precursor $\left(\mathrm{TiOSO}_{4}\right)$ are attributed to the hydrolysis reaction initiation. Hexagonally structure was formed in only cationic surfactant micellar solutions while no ordered structure was formed in PAH and formamide solutions. So surfactant micelles play an important role for the formation of the hexagonally structure as structure-directed agents and/or templates.

\section{EXPERIMENTAL}

Hex-ncTiO ${ }_{2} /$ CTAB Nanoskeleton was prepared through hydrolysis reaction and polymorphic crystallization after mixing of cetyltrimethylammonium bromide $\left(\mathrm{C}_{16} \mathrm{H}_{33} \mathrm{~N}\left(\mathrm{CH}_{3}\right)_{3} \mathrm{Br}\right.$; CTAB, Aldrich) and titanium oxysulfate acid hydrate $\left(\mathrm{TiOSO}_{4} \cdot \mathrm{xH}_{2} \mathrm{SO}_{4} \cdot \mathrm{xH}_{2} \mathrm{O}\right.$; Aldrich) as a titania precursor in aqueous solutions, at different temperatures (in the range of $40-60^{\circ} \mathrm{C}$ ) and at the various mixing ratios of the titania precursor/CTAB (in the range of 2-50 molar ratio, CTAB concentration is fixed to be $60 \mathrm{mM}$ ). The titanium oxysulfate acid hydrate dissolves in water as titanium(IV) sulfate $\left(\right.$ Fig. 1) ${ }^{28)}$. Sodium dodecyl sulfate

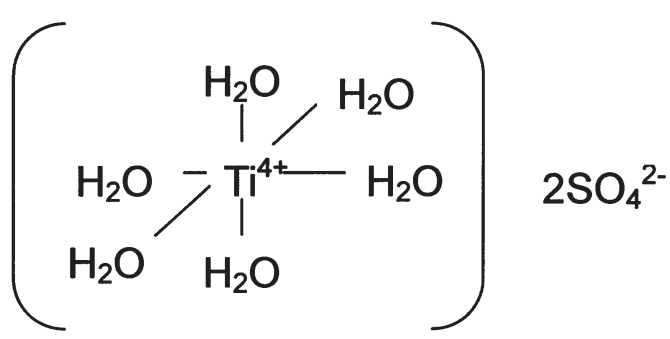

Fig. 1 Structure of Titanium(IV) Sulfate.

$\left(\mathrm{CH}_{3}\left(\mathrm{CH}_{2}\right)_{11} \mathrm{OSO}_{3} \mathrm{Na}\right.$; SDS, Kanto Chemical Co., Inc.) was used to examine the effect of electrostatic interactions between surfactants and the titanium(IV) sulfate on hydrolysis reaction initiation and polymorphic crystallization. Polycation, poly(allylamine hydrochloride) $\left(\left[\mathrm{CH}_{2} \mathrm{CH}\right.\right.$ $\left.\left(\mathrm{CH}_{2} \mathrm{NH}_{2}\right) \mathrm{HCl}\right]_{n}$, average molecular weight $\sim 70,000$; $\mathrm{PAH}$, Aldrich), allows us to evaluate roles of cationic surfactant micelles on the hexagonally structure formation because PAH does not form micelles. For comparison purpose with $\mathrm{PAH}$, polyanion, poly(sodium 4-styrenesulfonate) $\left(\left[\mathrm{C}_{8} \mathrm{H}_{7} \mathrm{NaO}_{3} \mathrm{~S}\right]_{n}\right.$, average molecular weight $\sim 70,000$; PSSS, Aldrich) was tested to prepare titania. The effect of interactions between nitrogen atom in a molecule and titanium(IV) sulfate was investigated using formamide $\left(\mathrm{HCONH}_{2}\right.$, Kanto Chemical Co., Inc.) as a solvent because a formamide molecule contains a nitrogen atom without any ionic parts.

Ordered structure, crystal type and crystallinity of titania that we obtained were characterized with powder Xray diffraction (XRD) (RINT1100, $\mathrm{CuK} \alpha$ radiation, RIGAKU), small-angle X-ray scattering (SAXS) (SAXSees, Anton Paar, PANalytical) with PW3830 laboratory X-ray generator with a long fine focus sealed glass X-ray tube ( $K \alpha$ wavelength of $0.1542 \mathrm{~nm}$ ) (PANalytical) and operated at $40 \mathrm{kV}$ and $50 \mathrm{~mA}$, and transmission electron microscopy (TEM) (H-7650, Hitachi High Technology, 120 kV, $3.0 \mu \mathrm{A}$ ), after precipitates (titania) obtained were filtered, washed by water, and dried at $120^{\circ} \mathrm{C}$ for $10 \mathrm{~h}$ under air atmosphere.

\section{RESULTS AND DISCUSSION}

\subsection{Formation of $\mathrm{Hex}-\mathrm{ncTiO}_{2} / \mathrm{CTAB}$ Nanoskeleton}

$\mathrm{Hex}-\mathrm{nc} \mathrm{TiO}_{2} / \mathrm{CTAB}$ Nanoskeleton was prepared with aging for $24 \mathrm{~h}$ at $60^{\circ} \mathrm{C}$ after mixing of the titania precursor and CTAB aqueous solutions (Figs. 2 and 3 ) following previous reports $^{20,211}$. TEM observation (Fig. 2), SAXS (upper panel of Fig. 3) and XRD (bottom panel of Fig. 3) measurements confirmed formation of Hex-ncTiO ${ }_{2} / \mathrm{CTAB}$ Nanoskeleton. Honeycomb-like structure with pore diameter of $\sim 3 \mathrm{~nm}$ (upper image of Fig. 2) and long-range lined structure (bottom image of Fig. 2) were observed by TEM. Noticeable three SAXS peaks were assigned to hexagonally structure 

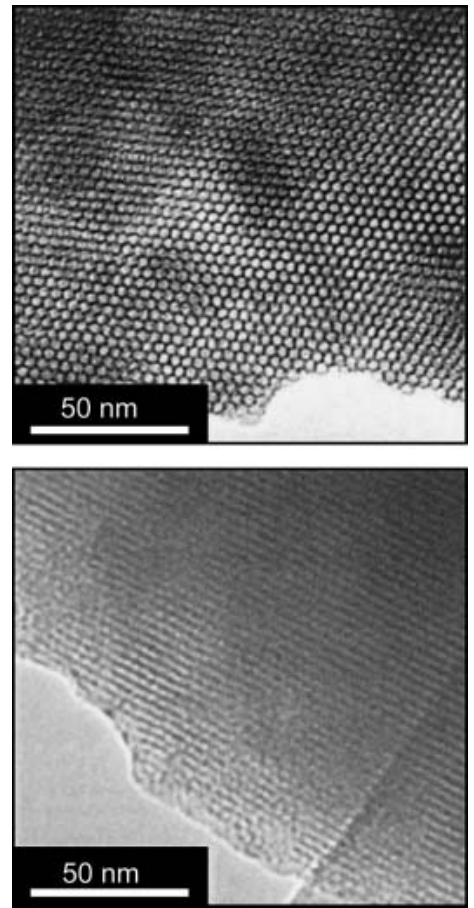

Fig. 2 TEM Images of Hex-ncTiO $/$ CTAB Nanoskeleton Prepared through Hydrolysis Reaction of the Titania Precursor $(3000 \mathrm{mM})$ and CTAB $(60 \mathrm{mM})$ in Aqueous Solutions at $60^{\circ} \mathrm{C}$ for $24 \mathrm{~h}$.

$\left(d_{100}: d_{110}: d_{200}=1: 1 / \sqrt{3}: 1 / 2\right)$ (upper panel of Fig. 3), and XRD peaks were assigned to crystalline anatase ((101), (004), (200) and (105) facets) (bottom panel of Fig. 3) ${ }^{29,30}$. The value of $d_{100}$ spacing $(\sim 4 \mathrm{~nm})$ calculated by Bragg's equation $^{30)}$ was consistent with sum of the pore diameter of $\sim 3$ $\mathrm{nm}$ and framework thickness of $\sim 1 \mathrm{~nm}$ observed by TEM.

In order to realize the formation mechanism of HexncTiO ${ }_{2} /$ CTAB Nanoskeleton, SAXS and XRD patterns of $\mathrm{TiO}_{2} / \mathrm{CTAB}$ Nanoskeleton were recorded as a function of the elapsed time after mixing of the titania precursor and CTAB in aqueous solutions (Fig. 4). Noticeable three SAXS peaks corresponding to hexagonally structure $\left(d_{100}: d_{110}\right.$ : $d_{200}=1: 1 / \sqrt{3}: 1 / 2$ ) were observed immediately after mixing of the titania precursor and $\mathrm{CTAB}$ in aqueous solutions $(0 \mathrm{~h})$ (upper panel of Fig. 4), while no significant XRD peak was observed in the same sample $(0 \mathrm{~h})$ (bottom panel of Fig. 4). This indicates that hexagonal-structured amorphous titania (hydrated titania or titanium(IV) oxide)/CTAB Nanoskeleton (Hex-amTiO $2 /$ CTAB Nanoskeleton) with $d_{100}$ spacing of $\sim 4 \mathrm{~nm}$ was formed immediately after mixing of aqueous solutions containing the titania precursor and CTAB spherical micelles. The SAXS peaks corresponding to hexagonally structure were retained up to $48 \mathrm{~h}$, and following those peaks became broader (upper panel of Fig. 4). On the other hand, the XRD peaks assigned to crystalline
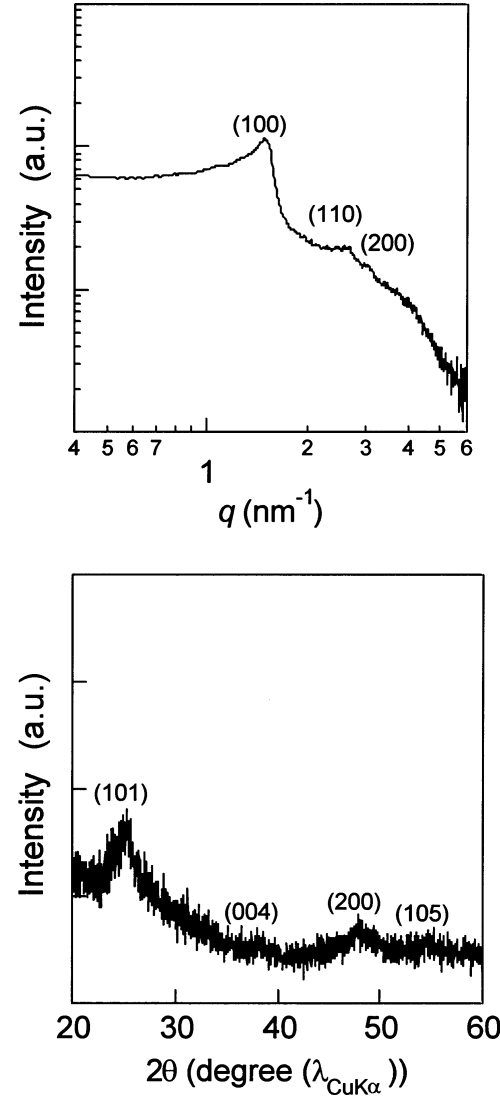

Fig. 3 SAXS (upper panel) and XRD (bottom panel) Patterns of Hex-ncTiO ${ }_{2} /$ CTAB Nanoskeleton Prepared through Hydrolysis Reaction of the Titania Precursor $(3000 \mathrm{mM})$ and CTAB $(60 \mathrm{mM})$ in Aqueous Solutions at $60^{\circ} \mathrm{C}$ for $24 \mathrm{~h}$.

anatase ((101), (004), (200) and (105) facets ${ }^{29,30)}$ became more significant and sharper with aging (bottom panel of Fig. 4). These results allow us to propose the formation mechanism of Hex-nc $\mathrm{TiO}_{2} / \mathrm{CTAB}$ Nanoskeleton as follows; Hex$\mathrm{amTiO}_{2} / \mathrm{CTAB}$ Nanoskeleton is formed immediately after mixing of the titania precursor and CTAB micellar aqueous solutions, and the amorphous titania (hydrated titania or titanium(IV) oxide) changes to $\mathrm{Hex}-\mathrm{ncTiO}_{2} / \mathrm{CTAB}$ Nanoskeleton with aging through hydrolysis reaction and polymorphic crystallization (proposed mechanism in Fig. $5)$.

\subsection{Crystal growth and hexagonally structure formation}

We realized that the $\mathrm{Hex}-\mathrm{amTiO}_{2} / \mathrm{CTAB}$ Nanoskeleton initially formed changed to the $\mathrm{Hex}-\mathrm{ncTiO}_{2} / \mathrm{CTAB}$ Nanoskeleton (with retaining $d_{100}$ spacing of $\sim 4 \mathrm{~nm}$ ) through hydrolysis reaction and polymorphic crystallization with elapsed time (bottom panel of Fig. 4). Namely, crystalline titania was formed through the polymorphic crystallization of the amorphous titania (hydrated titania 
T. Sakai, H. Yano, M. Ohno et al.
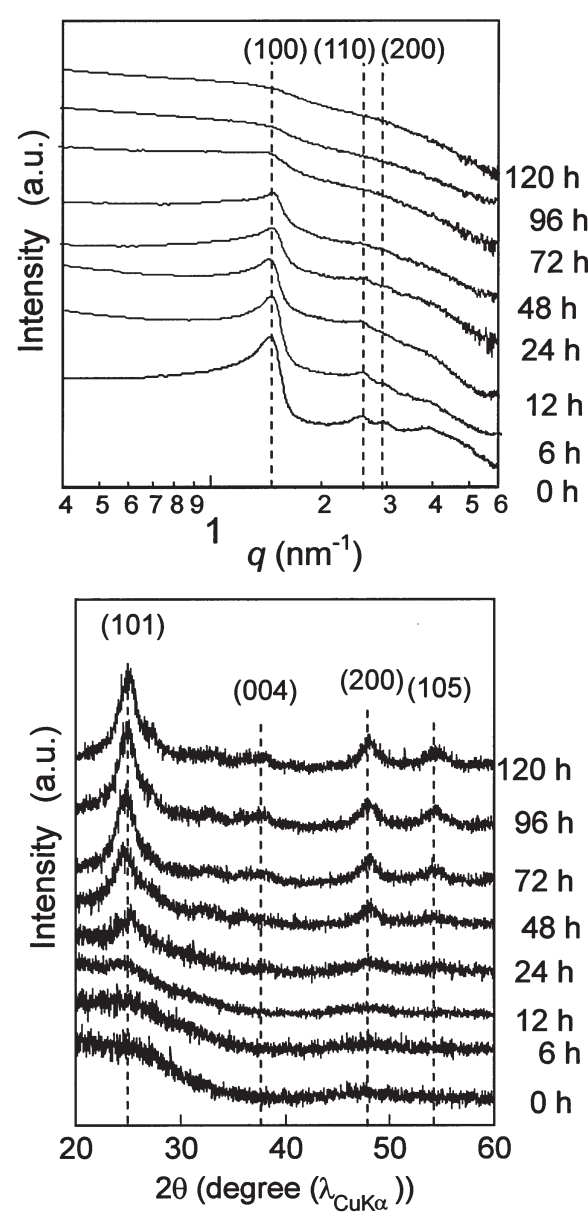

Fig. 4 SAXS (upper panel) and XRD (bottom panel) Patterns of $\mathrm{Hex}-\mathrm{TiO}_{2} / \mathrm{CTAB}$ Nanoskeleton Recorded as a Function of the Elapsed Time after Mixing of the Titania Precursor $(3000 \mathrm{mM})$ and CTAB (60 $\mathrm{mM})$ in Aqueous Aolutions at $60^{\circ} \mathrm{C}$.

or titanium(IV) oxide) in the $\mathrm{Hex}-\mathrm{amTiO}_{2} / \mathrm{CTAB}$ Nanoskeleton. Then, in order to evaluate the mechanism on the crystal growth and hexagonally structure formation, time evolutions of SAXS and XRD patterns were monitored at various temperatures (in the range of $40-60^{\circ} \mathrm{C}$ ) and the titania precursor/CTAB mixing ratios (in the range of 2-50 molar ratio). We found that the growth of crystalline (anatase) titania was affected by temperature and the titania precursor/CTAB mixing ratio (Fig. 6). On the other hand, the hexagonal-structure of $\mathrm{amTiO}_{2} / \mathrm{CTAB}$ and ncTiO $\mathrm{T}_{2} / \mathrm{CTAB}$ Nanoskeleton was always formed in the temperature range $\left(40-60^{\circ} \mathrm{C}\right)$ and titania precursor/CTAB mixing ratio range (2-50 molar ratio) that we applied in this work (only the results obtained at $60^{\circ} \mathrm{C}$ and at the titania precursor/CTAB mixing ratio of 50 are shown in Fig. 4). Crystal (200) facet sizes (estimated by Sherrer equation ${ }^{30}$ ) of the Hex-ncTiO ${ }_{2} /$ CTAB Nanoskeleton plotted in Fig. 6 as
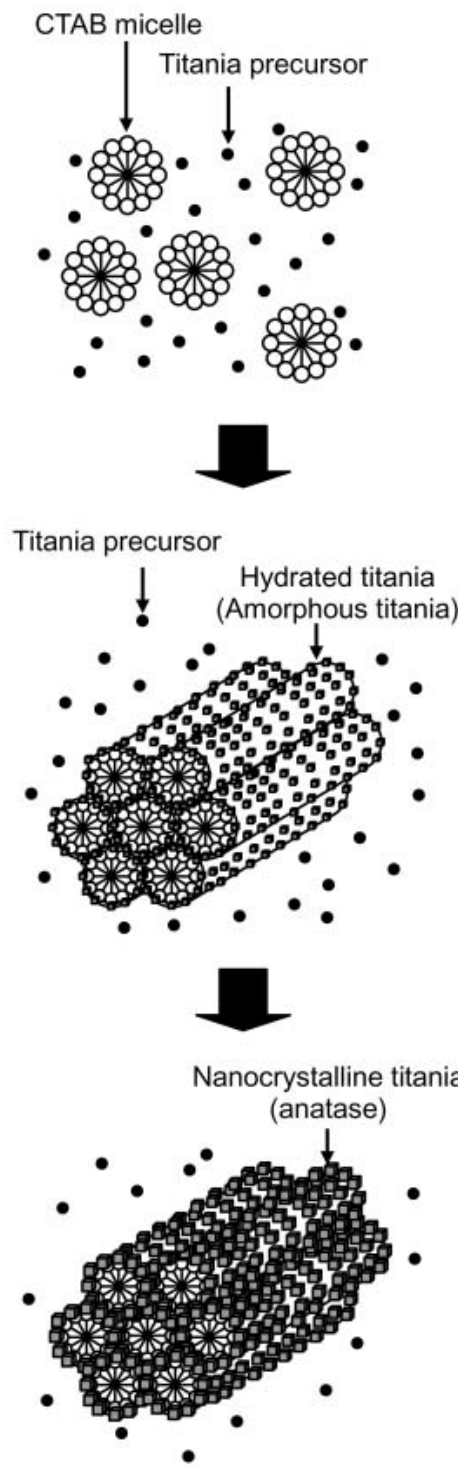

Fig. 5 Proposed Mechanism of Hex-ncTiO $2 / \mathrm{CTAB}$ Nanoskeleton Formation.

a function of time showed that the crystal growth was enhanced with higher temperature (with order of $40<50$ $<60^{\circ} \mathrm{C}$ ). The crystal growth of nanocrystalline titania at $25^{\circ} \mathrm{C}$ was much slower than at $40^{\circ} \mathrm{C}$ (the result is not reported here). This indicates that temperature is one of the factors to control the crystal growth of titania (and/or hydrated titania) in the Hex-amTiO 2 /CTAB Nanoskeleton. This is reasonable because the hydrolysis reaction and polymorphic crystallization of titania precursor (and/or hydrated titania) are enhanced at higher temperature ${ }^{22-27)}$. In addition, crystal growth of the titania (and/or hydrated titania) is promoted with lower titania precursor content in solutions (with order of the titania precursor/CTAB mixing ratios $=50<30<10$ molar ratio). This is most likely 

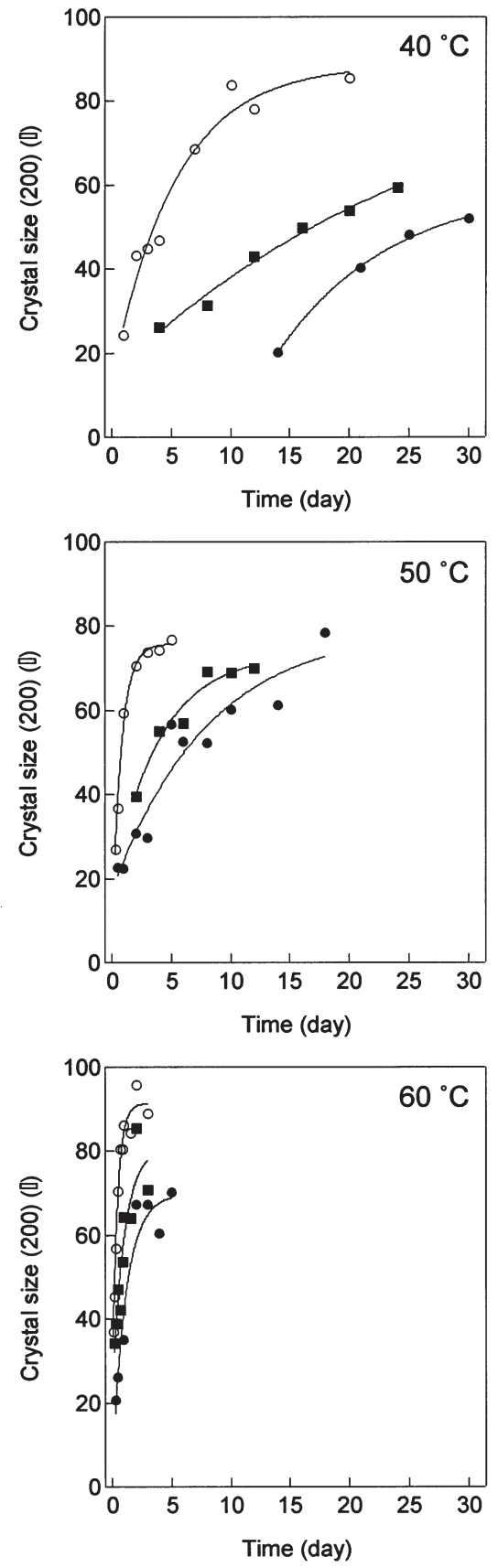

Fig. 6 Effects of Mixing Ratio of the Titania Precursor/CTAB $(=10(\bigcirc), 30(\boldsymbol{\square})$ and $50(\mathbf{O})$ molar ratio) on Crystal Growth of Hex$\mathrm{ncTiO}_{2} / \mathrm{CTAB}$ Nanoskeleton at $40^{\circ} \mathrm{C}$ (top panel), $50^{\circ} \mathrm{C}$ (middle panel) and $60^{\circ} \mathrm{C}$ (bottom panel).

Crystal (200) facet sizes estimated by Sherrer equation plotted as a function of time. due to the different acid $\left(\mathrm{H}_{2} \mathrm{SO}_{4}\right)$ concentrations afforded by the titania precursor content in solutions. The titania precursor $\left(\mathrm{TiOSO}_{4} \cdot \mathrm{xH}_{2} \mathrm{SO}_{4} \cdot \mathrm{xH}_{2} \mathrm{O}\right)$ that we used in this experiments contains $\mathrm{H}_{2} \mathrm{SO}_{4}$, so the acid concentration is changed by the titania precursor content in solutions. Indeed, $\mathrm{pH}$ values of the titania precursor solutions were 1.10, 0.82 and 0.66, at titania precursor concentrations of 600, 1800 and $3000 \mathrm{mM}$, respectively. Namely, weaker acid conditions due to the lower titania precursor content in solutions most likely promote the crystal growth of titania (and/or hydrated titania) in the $\mathrm{Hex}-\mathrm{amTiO}_{2} / \mathrm{CTAB}$ Nanoskeleton because the hydrolysis reaction of titanium(IV) sulfate is normally initiated with the addition of base solutions ${ }^{28,31}$. These findings suggests that formation of the Hex-ncTiO ${ }_{2} / \mathrm{CTAB}$ Nanoskeleton is attributed to two hydrolysis reaction; (i) hydrolysis promoted by CTAB immediately after mixing of the titania precursor and $\mathrm{CTAB}$ in aqueous solutions, which contributes to the formation of hexagonal-structured self-assemblies of amorphous titania (Hex-amTiO $/$ CTAB), and (ii) hydrolysis promoted by temperature and acid/base balance that contributes to the growth of amorphous titania to crystalline titania.

\subsection{Hydrolysis reaction initiation and hexagonally structure formation}

We now considered that formation of the HexncTiO ${ }_{2} /$ CTAB Nanoskeleton is attributed to the (i) hydrolysis promoted by CTAB immediately after mixing of the titania precursor and CTAB in aqueous solutions, and (ii) hydrolysis with aging promoted by temperature ${ }^{22-27)}$ and acid/base balance ${ }^{28,31}$. The effects of temperature and acid/base balance on the hydrolysis reaction are well known in crystal growth of titania ${ }^{22-28,311}$. However, the hydrolysis reaction promoted by CTAB involves questions because the CTAB aqueous solution itself is not base $(\mathrm{pH}$ value of the CTAB aqueous solution that we used in this experiment is $\sim 7$ ). In general, titania (precipitate) is hardly formed in acid solutions due to the slow hydrolysis reaction of titanium(IV) sulfate in acid solutions ${ }^{28,31}$. Indeed, the hydrolysis reaction and the resulting titania precipitate were not observed in the $\mathrm{TiOSO}_{4} \cdot \mathrm{xH}_{2} \mathrm{SO}_{4} \cdot \mathrm{xH}_{2} \mathrm{O}$ aqueous solution for a couple days (Fig. 7f). This is most likely due to the strong acid solution (with $\mathrm{pH}<1$ ). However, white precipitate (titania) appeared immediately after mixing of the titania precursor $\left(\mathrm{TiOSO}_{4} \cdot \mathrm{xH}_{2} \mathrm{SO}_{4} \cdot \mathrm{xH}_{2} \mathrm{O}\right)$ and $\mathrm{CTAB}$ aqueous solutions (Fig. 7a). As described in previous section, the white precipitate was composed of Hex$\mathrm{amTiO}_{2} / \mathrm{CTAB}$ Nanoskeleton. This obviously indicates that $\mathrm{CTAB}$ promotes the hydrolysis reaction of titanium(IV) sulfate even in strong acid solutions.

Then, we examined the effects of electrostatic interaction on the hydrolysis reaction initiation to evaluate roles of CTAB on hydrolysis initiation, because an electrostatic 

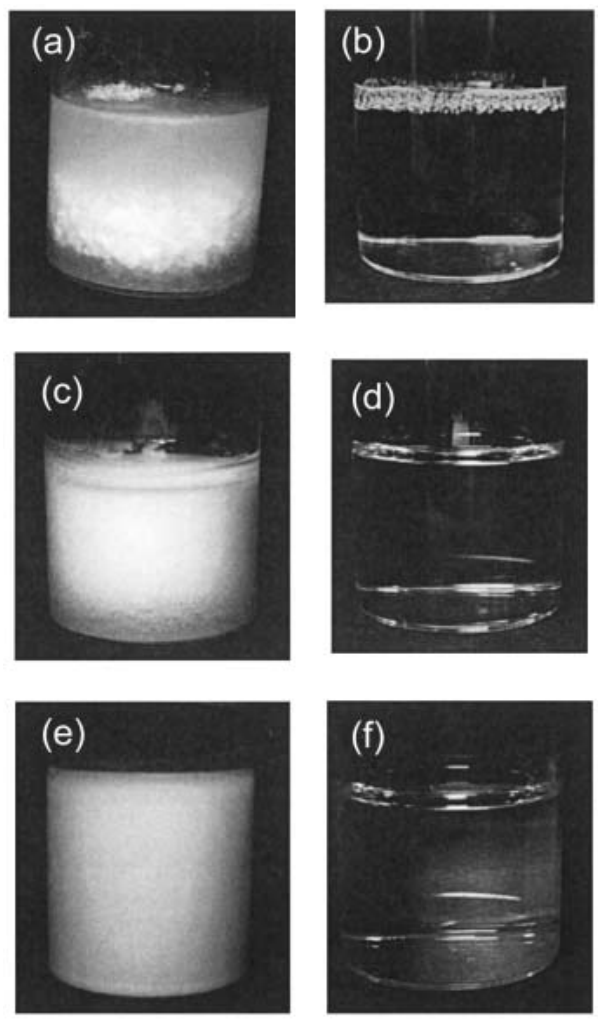

Fig. 7 Solutions Obtained after Mixing of the Titania Precursor $\left(\mathrm{TiOSO}_{4} \cdot \mathrm{xH}_{2} \mathrm{SO}_{4} \cdot \mathrm{xH}_{2} \mathrm{O}\right)$ with (a) $\mathrm{CTAB}_{\mathrm{aq}}$, (b) $\mathrm{SDS}_{\mathrm{aq} \cdot}$, (c) $\mathrm{PAH}_{\mathrm{aq}}$, (d) $\mathrm{PSSS}_{\mathrm{aq}}$. (e) Formamide and (f) Water, respectively.

interaction between surfactants and inorganic precursors contribute to the polymorphic crystallization and formation of ordered structure (e.g., hexagonal, cubic, lamellar structures $)^{8,12,13,22-27)}$. Anionic surfactant, SDS micellar aqueous solution was tested to prepare titania because titanium(IV) sulfate has positive charge. However, titania (precipitate) did not form in SDS aqueous solutions (Fig. 7b). In addition to the anionic (SDS) micellar system, we also tested polyanion, PSSS aqueous solutions for titania formation, but this also did not work for titania formation (Fig. $7 \mathrm{~d})$. These indicate that the electrostatic interaction is not directly contributed to the hydrolysis reaction initiation in the case of the titania precursor $\left(\mathrm{TiOSO}_{4} \cdot \mathrm{xH}_{2} \mathrm{SO}_{4} \cdot \mathrm{xH}_{2} \mathrm{O}\right)$. This suggests that cationic group in a CTAB molecule has particular roles to initiate the hydrolysis reaction. So we tested titania formation in polycation, $\mathrm{PAH}$ aqueous solutions. Indeed, white precipitation appeared immediately after mixing of the titania precursor and $\mathrm{PAH}$ aqueous solutions (Fig. 7c), and crystalline anatase titania was obtained with aging for $24 \mathrm{~h}$ at $60^{\circ} \mathrm{C}$ in $\mathrm{PAH}$ aqueous solutions (bottom panel of Fig. 8). This supports the contribution of cation group to the hydrolysis reaction initiation.
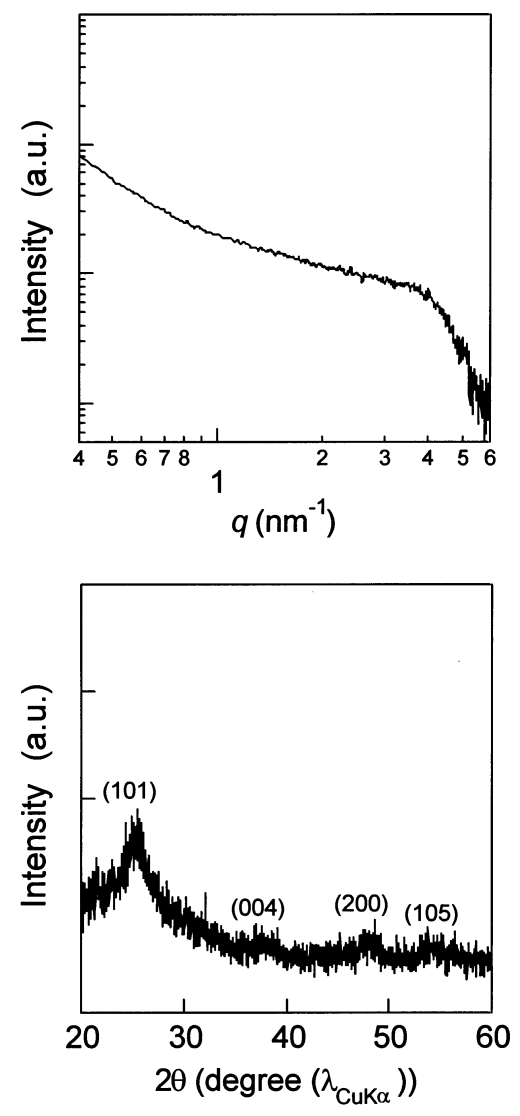

Fig. 8 SAXS (upper panel) and XRD (bottom panel) Patterns of Titania Precipitate Prepared through Mixing of the Titania Precursor $(3000 \mathrm{mM})$ and PAH (2wt\%) in Aueous Solutions at $60^{\circ} \mathrm{C}$ for $24 \mathrm{~h}$.

Here, one more question arise; which is a main contributor between cationic groups or nitrogen atoms in CTAB and $\mathrm{PAH}$ to the hydrolysis reaction. In order to address this question, we used formamide that involves nitrogen atom in a molecule but no ionic part. White precipitation was also obtained by just dissolving of the titania precursor $\left(\mathrm{TiOSO}_{4} \cdot \mathrm{xH}_{2} \mathrm{SO}_{4} \cdot \mathrm{xH}_{2} \mathrm{O}\right.$ ) in formamide (Fig. 7e), and the resulting titania precipitate was crystalline (anatase) titania (bottom panel of Fig. 9). These findings indicate that nitrogen atoms themselves in molecules (polymers) play an important role for the hydrolysis reaction initiation, in the case of $\mathrm{TiOSO}_{4} \cdot \mathrm{xH}_{2} \mathrm{SO}_{4} \cdot \mathrm{xH}_{2} \mathrm{O}$ aqueous solutions. This also suggests that nitrogens in molecules provide a particular reaction site (e.g., base condition) or react directly with titanium(IV) sulfate. Furthermore, we found that hexagonally structure is formed in only CTAB micellar solutions but not in polyanion (PAH) or formamide solutions (upper panel of Figs. 3, 8 and 9). No noticeable SAXS peaks originating from ordered structure such as hexagonally structure were observed in the case of polyanion $(\mathrm{PAH})$ or for- 

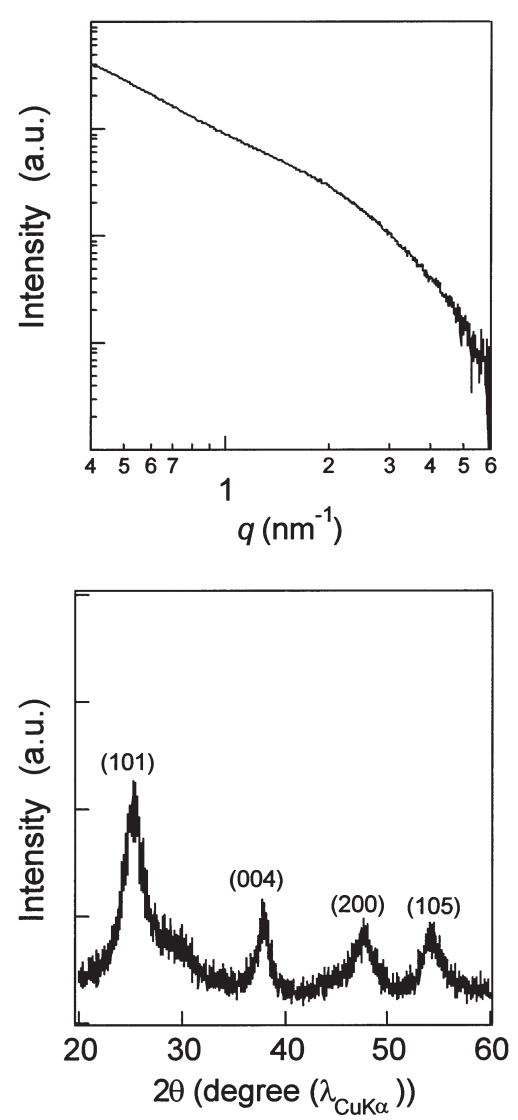

Fig. 9 SAXS (upper panel) and XRD (bottom panel) Patterns of Titania Precipitate Obtained through the Reaction of Titania Precursor $(3000 \mathrm{mM})$ with Formamide at $60^{\circ} \mathrm{C}$ for $24 \mathrm{~h}$.

mamide solutions (upper panel of Figs. 8 and 9). We also confirmed formation of Hex-nc $\mathrm{TiO}_{2} / \mathrm{C}_{n} \mathrm{TAB}$ using alkyltrimethylammonium bromides $\left(\mathrm{C}_{n} \mathrm{H}_{2 n+1} \mathrm{~N}\left(\mathrm{CH}_{3}\right)_{3} \mathrm{Br}\right.$; $\mathrm{C}_{n} \mathrm{TAB},{ }_{n}=12,14,16$ and 18 ) (this result will be reported elsewhere). So we realized that micelles are required for the hexagonally structure formation in our system. The hexagonally structure formation from spherical micelles during the hydrolysis reaction and polymorphic crystallization is most likely related to the condensation (phase transition) of surfactant self-assemblies caused by the interaction, complexation and/or reaction between $\mathrm{C}_{n} \mathrm{TAB}$ and titanium(IV) sulfate ${ }^{8-13)}$. As described above, nitrogens in molecules (e.g., $\mathrm{C}_{n} \mathrm{TAB}$ ) provide a particular reaction site (e.g., base condition) or react directly with titanium(IV) sulfate. So the interaction, complexation and/or reaction between $\mathrm{C}_{n} \mathrm{TAB}$ and titanium(IV) sulfate would produce a condensed phase of $\mathrm{C}_{n} \mathrm{TAB}$-titanium(IV) sulfate complexes in solutions. The white precipitate that we obtained immediately after mixing of the titania precursor and $\mathrm{C}_{n} \mathrm{TAB}$ in aqueous solutions would be the condensed phase in solu- tion. Namely, the hexagonally structure formation is most likely due to the condensation by the complexation (reaction) of titanium(IV) sulfate with $\mathrm{C}_{n} \mathrm{TAB}$ micelles.

\section{CONCLUSIONS}

Formation mechanism of Hex-ncTiO ${ }_{2} /$ CTAB Nanoskeleton was examined in terms of temperature, titania precursor/CTAB mixing ratio, electrostatic interactions (charge), micelle formation and molecular component. Temperature and the titania precursor/CTAB mixing ratio contribute to the crystal growth but not to the hexagonally structure formation. The electrostatic interactions caused by molecular (micelle) charge did not contribute to the hydrolysis reaction initiation directly in the case of $\mathrm{TiOSO}_{4} \cdot \mathrm{xH}_{2} \mathrm{SO}_{4}$. $\mathrm{xH}_{2} \mathrm{O}$ as a titania precursor. On the other hand, small molecules and polymers containing nitrogens can promote the hydrolysis reaction initiation and polymorphic crystallization, while the hexagonally structure was not formed in the absence of micelles. This suggests that amphiphilic molecules containing nitrogens to form micelles are one of the candidates as structure-directing agents for the titania precursor $\left(\mathrm{TiOSO}_{4} \cdot \mathrm{xH}_{2} \mathrm{SO}_{4} \cdot \mathrm{xH}_{2} \mathrm{O}\right)$ to build the hexagonalstructured crystalline anatase titania Nanoskeleton.

Our findings that we reported here provided better insight for fabrication of the ordered-structure materials, nucleation and crystal growth using water-soluble inorganic precursors such as $\mathrm{TiOSO}_{4} \cdot \mathrm{xH}_{2} \mathrm{SO}_{4} \cdot \mathrm{xH}_{2} \mathrm{O}$. Judicious selection of amphiphilic molecules (as structure-directing agents and/or templates) and inorganic precursors should enable to tune the ordered-structure of materials and crystallinity of frameworks.

\section{ACKNOWLEDGMENT}

We are grateful to the Japan Aerospace Exploration Agency (Grant JDX-2005185A) for support of this research.

\section{References}

1. Lin, Y.; Alexandridis, P. Temperature-dependent adsorption of pluronic F127 block copolymers onto carbon black particles dispersed in aqueous media. $J$. Phys. Chem. B 106, 10834-10844 (2002).

2. Barnes, T.J.; Prestidge, C.A. PEO-PPO-PEO-block copolymers at the emulsion droplet-water interface. Langmuir 16, 4116-4121 (2000).

3. Modern Aspects of Emulsion Science (Binks, B.P. ed.). The Royal Society of Chemistry. Cambridge (1998).

4. Yang, L.; Alexandridis, P. Physicochemical aspects of drug delivery and release from polymer-based colloids. 
Curr. Opin. Colloid Interface Sci. 5, 132-143 (2000).

5. Kabanov, A.V.; Batrakova, E.V.; Alakhov, V.Y. Pluronic block copolymers as novel polymer therapeutics for drug and gene delivery. J. Controlled Release 82, 182212 (2002).

6. Ahmed, F.; Alexandridis, P.; Shankaran, H.; Neelamegham, S. The ability of poloxamers to inhibit platelet aggregation depends on their physicochemical properties. Thromb. Haemostasis 86, 1532-1539 (2001).

7. Cohn, D.; Sosnik, A.; Levy, A. Improved reverse thermo-responsive polymeric systems. Biomaterials 24, 3707-3714 (2003).

8. Advanced Catalysts and Nanostructured MaterialsModern Synthetic Methods. (Moser, R.M. ed.). Academic Press Inc., London (1996).

9. Corma, A. From microporous to mesoporous molecular sieve materials and their use in catalysis. Chem. Rev. 97 (6), 2373-2420 (1997).

10. Ying, J.Y.; Mehnert, C.P.; Wong, M.S. Synthesis and applications of supramolecular-templated mesoporous materials. Angew. Chem. Int. Ed. 38, 56-77 (1999).

11. Soler-Illia, G.J. de A.A.; Sanchez, C.; Lebeau, B.; Patarin, J. Chemical strategies to design textured materials: From microporous and mesoporous oxides to nanonetworks and hierarchical structures. Chem. Rev. 102, 4093-4138 (2002).

12. Beck, J.S.; Vartuli, J.C.; Roth, W.J.; Leonowicz, M.E.; Kresge, C.T.; Shmitt, K.D.; Chu, C.T.-W.; Olsen, D.H.; Sheppard, E.W.; McCullen, S.B.; Higgins, J.B.; Schlenker, J.L. A new family of mesoporous molecular sieves prepared with liquid crystal templates. J. Am. Chem. Soc. 114, 10834-10843 (1992).

13. Kresge, C.T.; Leonowicz, M.E.; Roth, W.J.; Vartuli, J.C.; Beck, J.S. Ordered mesoporous molecular sieves synthesized by a liquid-crystal template mechanism. Nature 359, 710-712 (1992).

14. Zhao, D.; Feng, J.; Huo, Q.; Melosh, N.; Fredrickson, G.H.; Chmelka, B.F.; Stucky, G.D. Triblock copolymer syntheses of mesoporous silica with periodic 50 to 300 angstrom pores. Science 279, 548-552 (1998).

15. Grosso, D.; Balkenende, A.R.; Albouy, P.A.; Ayral, A.; Amenistsch, H.; Babonneau, F. Two-dimensional hexagonal mesoporous silica thin films prepared from block copolymers: Detailed characterization and formation mechanism. Chem. Mater. 13, 1848-1856 (2001).

16. Joo, S.H.; Ryoo, R.; Kruk, M.; Jaroniec, M. Evidence for general nature of pore interconnectivity in 2-dimensional hexagonal mesoporous silicas prepared using block copolymer templates. J. Phys. Chem. B 106, 4640-4646 (2002).

17. Alberius, P.C.A.; Frindell, K.L.; Hayward, R.C.; Kramer, E.J.; Stucky, G.D.; Chmelka, B.F. General predictive syntheses of cubic, hexagonal, and lamellar silica and titania mesostructured thin films. Chem. Mater. 14,
3284-3294 (2002).

18. Soler-Illia, G.J. de A.A.; Crepaldi, E.L.; Grosso, D.; Sanchez, C. Block copolymer-templated mesoporous oxides. Curr. Opin. Colloid Interface Sci. 8, 109-126 (2003).

19. Flodstrom, K.; Wennerstrom, H.; Alfredsson, V. Mechanism of mesoporous silica formation. A time-resolved NMR and TEM study of silica-block copolymer aggregation. Langmuir 20, 680-688 (2004).

20. Shibata, H.; Ogura, T.; Mukai, T.; Ohkubo, T.; Sakai, H.; Abe, M. Direct synthesis of mesoporous titania particles having a crystalline wall. J. Am. Chem. Soc. 127, 16396-16397 (2005).

21. Shibata, H.; Mihara, H.; Mukai, T.; Ogura, T.; Kohno, H.; Ohkubo, T.; Sakai, H.; Abe, M. Preparation and formation mechanism of mesoporous titania particles having crystalline wall. Chem. Mater. 18, 2256-2260 (2006).

22. Soler-Illia, G.J.A.A.; Louis, A.; Sanchez, C. Synthesis and characterization of mesostructured titania-based materials through evaporation-induced self-assembly. Chem. Mater. 14, 750-759 (2002).

23. Yang, P.; Zhao, D.; Margolese, D.I.; Chmelka, B.F.; Stucky, G.D. Block copolymer templating syntheses of mesoporous metal oxides with large ordering lengths and semicrystalline framework. Chem. Mater. 11, 2813-2826 (1999).

24. Liu, K.S.; Zhang, M.L.; Shi, K.Y.; Fu, H.G. Large-pore mesoporous nanocrystalline titania thin films synthesized through evaporation-induced self-assembly. Mater. Lett. 59, 3308-3310 (2005).

25. Cassiers, K.; Linssen, T.; Mathieu, M.; Bai, Y.Q.; Zhu, H.Y.; Cool, P.; Vansant, E.F. Surfactant-directed synthesis of mesoporous titania with nanocrystalline anatase walls and remarkable thermal stability. J. Phys. Chem. B 108, 3713-3721 (2004).

26. Sreethawong, T.; Suzuki, Y.; Yoshikawa, S. Synthesis, characterization, and photocatalytic activity for hydrogen evolution of nanocrystalline mesoporous titania prepared by surfactant-assisted templating sol-gel process. J. Solid State Chem. 178, 329-338 (2005).

27. Cecilia Fuertes, M.; Soler-Illia, G.J.A.A. Processing of macroporous titania thin films: From multiscale functional porosity to nanocrystalline macroporous $\mathrm{TiO}_{2}$. Chem. Mater. 18, 2109-2117 (2006).

28. Maki, T. Effect of $\mathrm{pH}$ of titanium sulfate solution on properties of hydrous titanium(IV) oxide precipitated from the solution. Nippon Kagaku Kaishi (7), 945-955 (1978).

29. Zhang, H.; Banfield, J.F. Kinetics of crystallization and crystal growth of nanocrystalline anatase in nanometer-sized amorphous titania. Chem. Mater. 14, 41454154 (2002).

30. X-Ray Diffraction Procedures For Polycrystalline 
and Amorphous Materials, (Klug, H.P.; Alexander, L.E. ed.). John Wiley \& Sons Inc., New York (1974).

31. Izumi, F. The polymerphic crystallization of titanium(IV) oxide under hydrothermal conditions. II.
The roles of inorganic anions in the nucleation of rutile and anatase from acid solutions. Bull. Chem. Soc. Jpn. 51, 1771-1776 (1978). 